\title{
High Stakes Decisions Under Uncertainty: Dams, Development and Climate Change in the Rufiji River Basin
}

\author{
Christian Siderius, Robel Geressu, Martin C. Todd, \\ Seshagivi Rao Kolusu, Julien J. Harou, \\ Japhet J. Kashaigili, and Declan Conway
}

\begin{abstract}
The need to stress test designs and decisions about major infrastructure under climate change conditions is increasingly being recognised. This chapter explores new ways to understand and-if possible-reduce the uncertainty in climate information to enable its use in assessing decisions that have consequences across the water, energy, food and environment sectors. It outlines an approach, applied in the Rufiji River Basin in Tanzania, that addresses uncertainty in climate model
\end{abstract}

\footnotetext{
C. Siderius $(\bowtie)$

Grantham Research Institute on Climate Change and the Environment, London School of Economics and Political Science, London, UK

Uncharted Waters Research, Sydney, NSW, Australia

e-mail: c.siderius@lse.ac.uk

R. Geressu • J. J. Harou

University of Manchester, Manchester, UK

(C) The Author(s) 2021

D. Conway, K. Vincent (eds.), Climate Risk in Africa, https://doi.org/10.1007/978-3-030-61160-6_6
} 
projections by weighting them according to different skill metrics; how well the models simulate important climate features. The impact of different weighting approaches on two river basin performance indicators (hydropower generation and environmental flows) is assessed, providing an indication of the reliability of infrastructure investments, including a major proposed dam under different climate model projections. The chapter ends with a reflection on the operational context for applying such approaches and some of the steps taken to address challenges and to engage stakeholders.

Keywords Tanzania $\bullet$ Infrastructure $\bullet$ Model evaluation $\bullet$ Hydropower

\section{Adaptation Decision-Making in TanZania's RUfiJI RIVER BASIN}

Major investment decisions about infrastructure have long-term consequences that require anticipation of the future socio-economic and climate conditions under which they will function (Hallegatte et al. 2012). While there is evidence for cost-effectiveness of making infrastructure investments climate resilient, many decisions still fail to consider climate risk sufficiently, if at all (Global Commission on Adaptation 2019).

Large water-related investment decisions are currently under consideration in the Rufiji River Basin to support Tanzania's ambition of establishing itself as a middle income, more industrialised country. The massive Julius Nyerere Hydropower Project (JNHPP, Fig. 6.1) -long planned and with the potential to double the country's electricity production-was approved in 2018 and preparations such as land clearing, river diversion

M. C. Todd • S. R. Kolusu

University of Sussex, Brighton, UK

J. J. Kashaigili

Sokoine University of Agriculture, Morogoro, Tanzania

D. Conway

Grantham Research Institute on Climate Change and the Environment, London School of Economics and Political Science, London, UK 


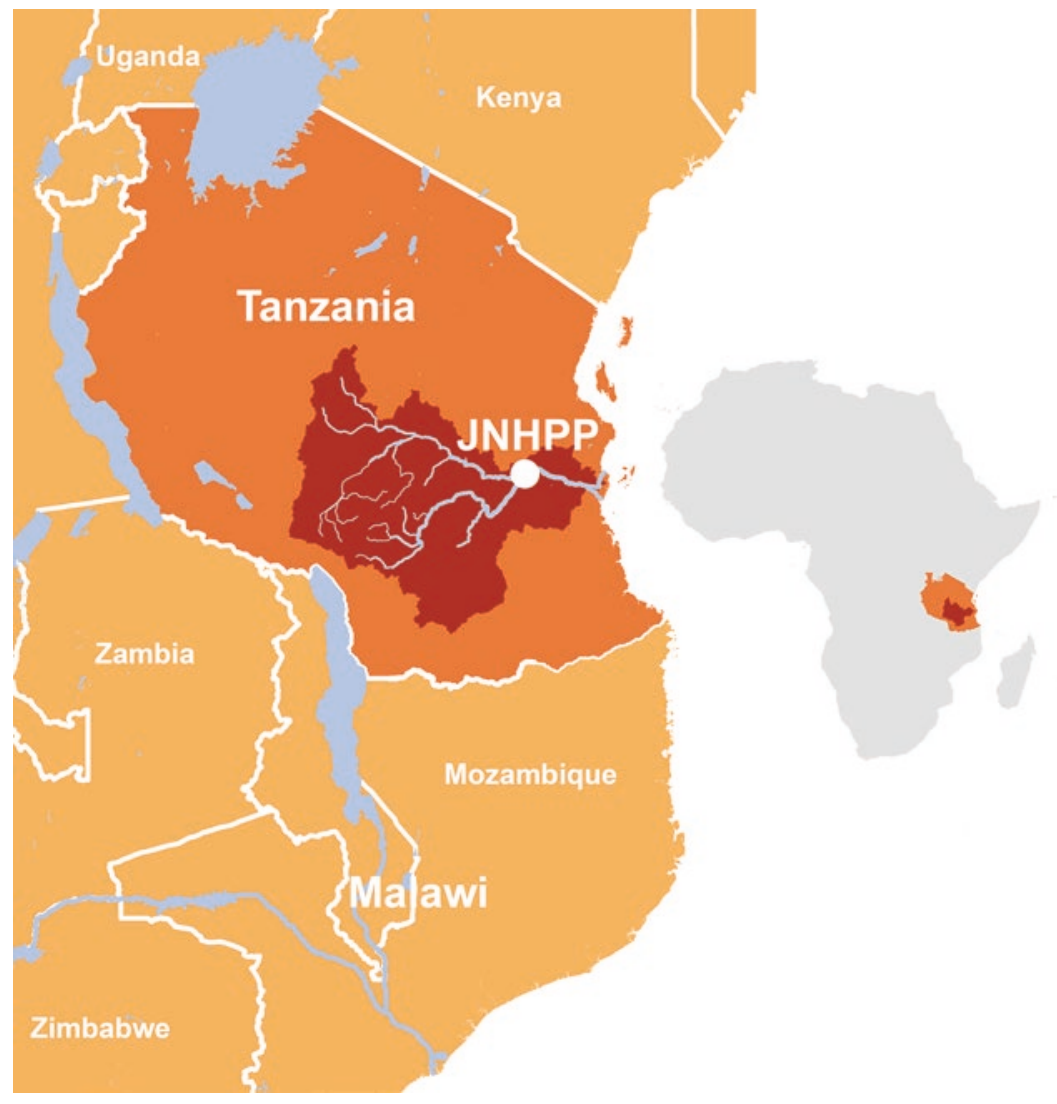

Fig. 6.1 The Rufiji River Basin in Tanzania, with the Julius Nyerere Hydropower Project (JNHPP)

tunnels and road infrastructure are in progress. When finished, this will be the second-largest dam by size in Africa. To boost agricultural production, Tanzania's new National Irrigation Master Plan (NIMP) and the Southern Agricultural Growth Corridor of Tanzania (SAGCOT) initiative identify massive scope for further irrigation expansion. To achieve this large investments are required, among many other things (the irrigation targets are very optimistic), in what are highly climate-sensitive sectors; the cost of constructing the JNHPP, excluding socio-environmental mitigation, is estimated at 4.7 billion US dollars against 2016 prices (Tanzania 
Government 2016). Moreover, such infrastructure has long lifetimes, with profound implications for future economic and social development trajectories, and as such can be considered to be 'high stakes' decisions. The Rufiji River Basin is the largest and most economically important river basin in Tanzania, producing half of Tanzania's river flow, supplying water for 4.5 million people and for irrigation and livestock, generating roughly $80 \%$ of the country's hydropower and supporting environmental flows in several major wildlife parks (Siderius et al. 2018). Alongside climate risk, there are important trade-offs between the effects of these developments across the water, energy, food and environment sectors (Duvail et al. 2014; Geressu et al. 2020; WWF International 2017) which require consideration given the challenge of achieving sustainable development in the basin.

Climate change in Tanzania and more widely in south-east Africa is characterised by large uncertainty, with climate models projecting wetter and drier conditions (Kolusu et al. 2021; UMFULA 2019). High levels of observed inter-annual and multi-annual rainfall variability dominate the historical record in the Rufiji River Basin. Rainfall records show a severe multi-year drought at the beginning of the twentieth century (Siderius et al. 2020). In recent years, droughts of shorter duration have, alongside management issues, exposed the vulnerability of existing hydropower in the basin. Occasional floods have further highlighted the management challenges of climate variability in this part of Africa (Siderius et al. 2020; UMFULA 2019). Experience in climate risk assessment has revealed a need to a focus on decision-relevant timescales, and to give greater attention to climate model evaluation (and the decisions therein-see Chaps. 1 and 2) and consideration of climate variability, within climate change analyses to help model projections become more useful in guiding local, practical adaptation (Conway and Schipper 2011; Nissan et al. 2019; Ray and Brown 2015).

Uncertainty about the future climate is compounded by the ad hoc nature of information provision and advice about climate change risks, leading to low consistency and confusion about the reliability and legitimacy of information-a concern that is echoed by several stakeholders in the Rufiji River Basin. Indeed, during consultations in the basin, stakeholders expressed a strong desire for more clarity, not only on the changes expected, but also on the differences between the myriad of climate model outcomes, their relevance to operational practice and preferably more specific information on the direction of change (for 
rainfall) and changes in extremes. The last two demands will remain difficult to meet as reduction in uncertainty of rainfall and the behaviour of extremes has proven elusive (Kolusu et al. 2021; Rowell et al. 2016). However, there is potential to portray a risk profile that includes uncertainty to aid the decision process surrounding major infrastructure such as the JNHPP.

UMFULA, a four-year research project under the Future Climate for Africa (FCFA) programme, tried to address these challenges by bringing together climate and impact scientists focussing on approaches to reduce uncertainty associated with differences between model projections. Infrastructure and basin management plans that work acceptably well under diverse sets of future conditions (robust solutions, or DecisionMaking Under Uncertainty-DMUU) are generally preferred over those that perform best under just one or a few climate projections. Major development agencies and donors are placing renewed emphasis on 'stress testing' infrastructure investments against multiple likely futures (Lempert and Schlesinger 2000; Ray and Brown 2015) but progress towards developing methods and for operationalising them has been slow. Large ensembles of climate models are readily available. At the same time, there is the understanding that climate models are not equally good nor are they truly independent of each other (Chap. 2; Knutti et al. 2010; Sanderson et al. 2017). In this chapter, we evaluate a specific DMUU approach applied in a developing country context that addresses the issue of uncertainty and climate model weighting in a stress testing exercise. Our aims are to (i) explore ways of constraining climate projection uncertainty through weighting and (ii) assess the impact of model weighting on infrastructure performance indicators.

\section{Aprroach}

We use the Rufiji River Basin in Tanzania as an example and illustrate the technical and practical implications of constraining and assessing the effects of uncertainty due to differences between climate model results. Though our study was performed without feeding into formal decisionmaking processes, our example design was informed by extensive consultation about the current decision context in the basin. We use climate impact simulation models developed and validated with local observations following discussion with agencies such as the Rufiji Basin Water Board and the Ministry of Water and Irrigation (Fig. 6.2, 

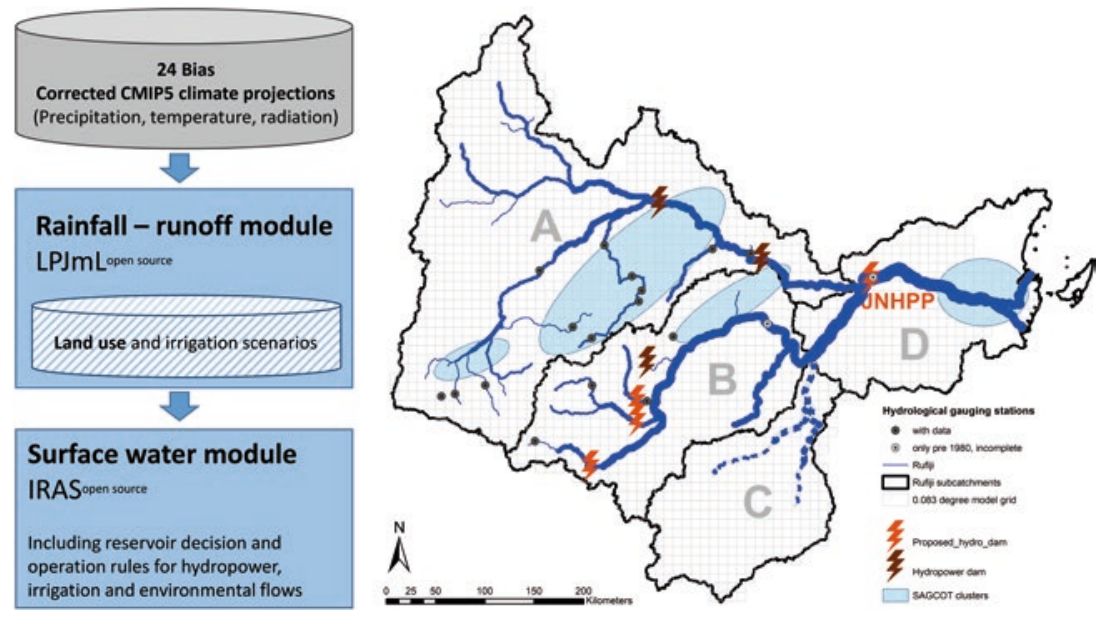

Fig. 6.2 System model schematic and basin map with main proposed dams and the SAGCOT clusters. Rufiji and main subcatchments: (a) Great Ruaha; (b) Kilombero; (c) Luwegu; (d) Lower Rufiji

Geressu et al. 2020; Siderius et al. 2018). The infrastructure development plans are adapted from the present river basin development plan (WREM International 2015).

Results presented in this chapter are based on an integrated suite of models consisting of a crop-hydrology model modified to local conditions, in combination with a water resources system model and a multi-objective search algorithm to evaluate development interventions in the basin (Geressu et al. 2020; Siderius et al. 2018). We consider a river basin design where all the proposed dams and potential irrigation sites are implemented, with operating rules of the dams set to maximise the minimum average annual energy generation in any one of the climate projections. We analysed a set of 24 climate models from the Coupled Model Intercomparison Project (CMIP5) that supported the Intergovernmental Panel on Climate Change (IPCC)'s Fifth Assessment Report. The model results were those available from a bias-correction exercise to allow for the difference between observations and model results over recent decades (Famien et al. 2018).

We use simulations of the historical period and the period 2021-2050 using the Representative Concentration Pathway (RCP) 8.5 forcing 
scenario (high rates of greenhouse gas emissions). Model weighting is derived via comparison of climate model simulations of past conditions (control climate, not yet corrected for bias) with historical observations based on the Global Precipitation Climatology Centre (GPCC) monthly rainfall version 7 (Schneider et al. 2017); and Climatic Research Unit (CRU) Temperature (Harris et al. 2014). The ability to simulate observed mean state, variability, drivers of variability such as the El Niño-Southern Oscillation and recent trend was evaluated, using a 'present-centric' approach (Chap. 2; Rowell 2019). In addition, we apply one 'future-specific' approach, whereby we try to understand the causes of climate projection spread among models and then relate this to how they simulate the present climate. We rule out projections according to several criteria. Specific detail on the weighting methods can be found in Kolusu et al. (2021).

Multiple stakeholder consultations were used to establish the river basin development alternatives and identify and prioritise important river basin performance metrics. These involved government staff (primarily in the Rufiji Basin Water Board and the Ministry of Water and Irrigation), hydrological and environmental researchers from universities and several locally active NGOs working on sustainability and development issues. Consultations took the form of small workshops (8-20 participants) held in March 2017, March and November 2018 and July 2019, complemented by informal discussions with many individuals between January 2016 and July 2019.

An initial longlist of performance indicators was narrowed down to seven after discussion with stakeholders, given their usefulness and major constraints due to very limited data availability in large parts of the basin. The seven indicators were: energy from hydropower, annual total, firm (reliable) annual and firm monthly; irrigation; total irrigated area, irrigation water demand deficit; environment; area flooded by the JNHPP and river flow disruption downstream in the lower Rufiji, which supports an important delta lake ecosystem, fisheries and flood recession irrigation. Here, we focus on indicators for two sectors that showed the strongest trade-offs: energy generation, both average annual and firm, and the impact on environmental flows in the Lower Rufiji (Table 6.1). We restrict our analysis of environmental flows to one indicator, disruption to the observed seasonal flow regime (which features a marked contrast between wet and dry season flows), noting that environmental flows are a 
Table 6.1 Final selection of decision relevant performance metrics for the water, energy and environment sectors in the Rufiji River Basin

\begin{tabular}{lll}
\hline Category & Performance metrics & Rationale \\
\hline Energy & $\begin{array}{l}\text { Total average annual } \\
\text { energy from all dams } \\
\text { in giga watt hour per } \\
\text { year (Gwh/year) }\end{array}$ & $\begin{array}{l}\text { Indicates potential energy generated from } \\
\text { existing and new reservoirs in a typical year }\end{array}$ \\
$\begin{array}{l}\text { Firm monthly energy } \\
\text { (Gwh/month) }\end{array}$ & $\begin{array}{l}\text { The monthly energy that is exceeded 99\% of the } \\
\text { time. It is a metric of how the energy generation } \\
\text { is distributed seasonally and the reliability of } \\
\text { energy supply }\end{array}$ \\
$\begin{array}{l}\text { Environmental } \\
\text { flows }\end{array}$ & $\begin{array}{l}\text { Extent to which the } \\
\text { observed seasonal } \\
\text { flow regime is } \\
\text { preserved (unit less } \\
\text { metric) }\end{array}$ & $\begin{array}{l}\text { Indicates a change in flow variability just } \\
\text { downstream of the JNHPP due to upstream } \\
\text { regulation. Maintaining present-day high } \\
\text { seasonal flow variability will benefit the Selous } \\
\text { lake ecosystem, flood recession agriculture and } \\
\text { ecosystem and fisheries in the Rufiji River delta }\end{array}$ \\
\hline
\end{tabular}

multi-faceted concept that include other aspects such as (peak) flow volumes and water quality.

\section{From Climate Uncertainty to Performance of Specific Sector Metrics}

In our bias-corrected climate model sample, most (19 out of 24) models project a modest to high increase in annual rainfall; the rainfall change for 2021-2050 compared to the near-present day (or baseline) period of 1980-2010 ranges between $-10 \%$ and $+30 \%$ (Fig. 6.3a). Note that in the larger set of available, non-bias corrected CMIP5 models, the distribution of rainfall change is more equally balanced between wetter and drier projections (not shown). This climate uncertainty is then both amplified and modified by hydrology (compare Fig. 6.3a, b); the largest changes in runoff are more pronounced, ranging from approximately $-30 \%$ to over $+60 \%$, and while the majority of models project an increase in rainfall, the impacts on runoff are more evenly distributed between drier and wetter futures. Increased transpiration by plants and crops due to higher temperatures can offset a projected increase in rainfall in some cases. An additional factor is the change in the distribution of rainfall over the season and between years. A relatively small redistribution in rainfall towards the 


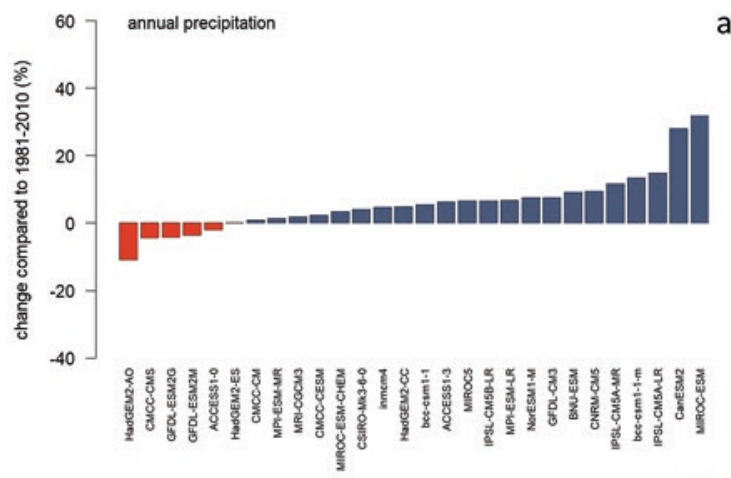

a
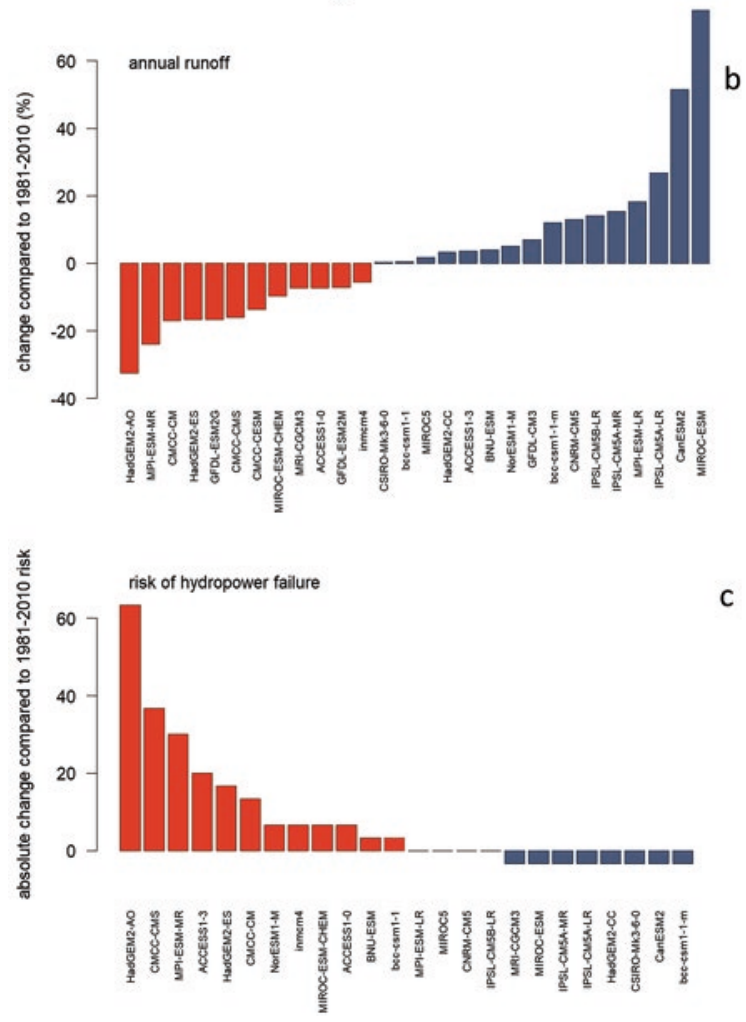

Fig. 6.3 (a) Projected change in rainfall, (b) river basin runoff at the JNHPP site near the outlet, and (c) the risk of a year with at least one month below a firm energy threshold in the JNHPP, comparing 2021-2050 to the baseline period 1981-2000, with model projections ranked from driest (in red) to wettest (in blue). Baseline hydropower risk is low, at 3.3\%. Results shown for a set of 24 biascorrected climate models 
onset period of the rainy season, with more isolated high-intensity rainfall events in October, November or December, and towards the months after the rainy season, in June and July, increases the fraction of rainfall that is absorbed by the soil and subsequently transpires through vegetation.

The range of uncertainty is further transformed when translated into impacts on specific water, energy and environment sector performance indicators. Figure $6.3 \mathrm{c}$ shows the change in future hydropower performance, expressed as the annual likelihood (in per cent) of failing to meet target monthly firm energy generation by the JNHPP. Under recent (1981-2010) climate conditions, according to our simulations, that likelihood would be once in 30 years (3.3\%). This likelihood is further reduced in the wetter projections, but it increases in the driest projection to over $60 \%$, that is, representing a failure to meet the target more than once in every two years. While the distribution in positive and negative impacts between projections is largely similar to the runoff change, nonlinear relationships between rainfall, runoff and hydropower generation mean the increase in likelihood of failure is amplified in the driest climate model projections.

Many of the projected increases or decreases in runoff are non-trivial; if the drier future becomes reality, this would constrain ambitions to become energy secure through the construction of the JNHPP because the expected firm energy would be greatly reduced. Further expansion of other forms of energy, such as solar and wind, might be considered to buffer energy supply in times of shortage. In cases of much wetter future conditions (e.g. some with up to $60 \%$ more runoff through the Rufiji River), major floods would likely become a much more regular occurrence. The scheme's flood release design might require re-evaluation under such extreme circumstances. While we have only focussed on one performance indicator for one sector, other sectors such as agriculture and the functioning of river dependent ecosystems also show highly contrasting impacts under this broad range of climate model results. We now consider if it is possible to reduce this uncertainty, by assessing the ability of models to realistically simulate past climate and exclude those that perform poorly. 


\section{Can We Reduce Uncertainty by Excluding Climate Model Projections?}

There is no established method for deciding upon which climate models to use for impact and risk assessment, although it is widely agreed that using only one model (or the average of many) and ignoring the range suggested by other available models is poor practice. Generally the 'go-to' source is the CMIP5 ensemble of models compiled for the IPCC Fifth Assessment. While there are many options available for selecting models, there is limited guidance and many questions arise, for example, should we use: All available models? Early versions and later versions of models? Exclude some models deemed to be poor performers or weight them less-but which reasons to use for excluding or weighting models? Moreover, how important are other practical considerations (time, expertise, cost) in decisions about model selection? Such issues are even more daunting if one considers using the regional climate model simulations available from the Coordinated Regional Climate Downscaling (CORDEX) programme, for example (Giorgi et al. 2009).

We explore these questions about model exclusion and weighting in the next section and examine the extent to which they have a bearing on endpoint decisions about adaptation. In particular, we focus on climate model realism (or skill) in simulating key features of African climate and use this to rank or weight (give different levels of influence to models with differing levels of skill) model selections (sub-samples) from a sample of 24 from CMIP5. We compare three methods of model weighting, noting that others could be used.

Figure 6.3 shows rainfall change for the Rufiji River Basin and impacts on runoff using an equal weighting of 24 climate models available from CMIP5, and Fig. 6.4 illustrates the effects of three different methods of weighting climate models on the range of impacts on runoff.

1. Binary inclusion/exclusion by rank based on skill. Models are assigned a weighting of either one or zero depending on their skill rank. Models are ranked from (1-24) according to a number of skill metrics, selected as key metrics of climate processes important to the region. The average rank across multiple metrics is derived and once ranked, the top $50 \%$ of the 24 models are selected and assigned a weight of one (Fig. 6.4a). All other models deemed 'unacceptable' are weighted zero (left blank). This is similar, for example, to the 



Fig. 6.4 Reducing uncertainty in projected annual runoff; (a) model ranking and binary inclusion (here selecting the top half best models), (b) a weighting approach (with the width of the bars representing the weight), and (c) a process based outlier detection approach. Model projections are ranked from the largest reduction in runoff (drier projections in red) to the largest increase in runoff (wetter projections in blue). Excluded models are shown in white 
ensemble subsetting approach developed by Rowell et al. (2016). As can be seen in Fig. 6.4a, the distribution of excluded models is similar between those that project a decrease and those that project an increase in runoff. However, the excluded models include the most extreme wet ones, which alters the profile of results, suggesting an overall more modest range of impacts.

2. Model weighting by skill and independence. Using the approach of Sanderson et al. (2017) from the US fourth National Climate Assessment, each model is assigned a weight which is the sum of a 'skill' weight (i.e. the model performance with respect to observations) and a model independence weight (i.e. the model performance with respect to all other models, such that models whose performance is similar to each other have reduced weighting). Figure $6.4 \mathrm{~b}$ shows that while it gives more weight to some models over others, the overall profile of impacts itself does not change. No model scores very well on all metrics, and similarly, no model scores badly on all metrics; it is a mixed bag with only some performing slightly better/worse than the majority, which means that the average scores are not that distinctive. That said, the highest score is a dry projection (CMCC-CM) while the lowest score is a wet projection (MIROC-ESM).

3. Model outlier weighting. In this approach, the 'outlier' models are identified, that is, those models whose climate change impacts are most extreme and hence likely to be associated with the highest costs of adaptation, something we wish to avoid if the models are low reliability. The models are then assessed in terms of how well they simulate extreme impacts, guided by our understanding of these mechanisms in present and future conditions. A weighting of zero is applied to models which are deemed unacceptable. The underpinning rationale is that adaptation decisions based on either a multi-model mean of climate projections or including the full ensemble are likely to be heavily influenced by any outlier models. Adaptation that is robust to climate change uncertainty may be more expensive if the uncertainty is skewed by outliers. It is therefore reasonable to assess whether such outliers are credible. Here, climate scientists of the UMFULA project identified several models that showed unrealistic behaviour over the historic measurement period in south-east Africa. In the subset of bias corrected models, these tend to be wetter [IPSL and MIROC models-see also Rowell (2019) for an evaluation of bias in the IPSL model] and their 
exclusion shifts the impact profile a little. However, we note that analysis using the larger CMIP5 set of 32 models found various drier projections were also deemed implausible (Kolusu et al. 2021).

All three methods reduce the dominance of projections of increased runoff but this effect is only small with the weighting approach (Fig. 6.4b). The effect of the ranking method is larger, but the decision about how many models to exclude is rather arbitrary and could be tested for significance against random exclusion of models (Fig. 6.4a). A process based approach with expert judgement (Fig. 6.4c) helps understanding of scientific reasons for the model range, but is much more time consuming and requires value judgements about which models are examined, how and the exclusion criteria.

\section{Performance Indicators Informed by Model Weighting}

Analysing the impact of different climate projections on outcomes of interest to decision-makers, such as firm or total energy production in the Rufiji River Basin, can highlight the sensitivity of decisions to uncertainty in climate projections. It can also help identify climate models with lower skill for a particular region and hence less credibility for use in actual decisions.

We apply this approach to the case of the Rufiji River Basin, using two performance indicators: total average annual energy generation and the impact on the seasonal variability of downstream flows (Table 6.1; Fig. 6.5). For this example, the Rufiji system is simulated assuming all proposed dams and potential irrigation sites are implemented. The operating rules of the dams are set to maximise the minimum average annual energy generation in any one of the climate projections; that is, reservoir operating rules of all dams, including the JNHPP, are optimised to operate at their best even under the most challenging projection (i.e. with low and variable inflows) for energy generation. This constitutes a form of robust decision-making as we do not know yet how the future climate will unfold. An alternative would be to try to assess the trajectory of climate change in the coming years and optimise operating rules accordingly, using those projections that seem to match this trajectory (adaptive management). However, especially in regions with strong interand multi-annual climate variability, such as in south-east Africa, reliably describing the trajectory of change will remain difficult. 


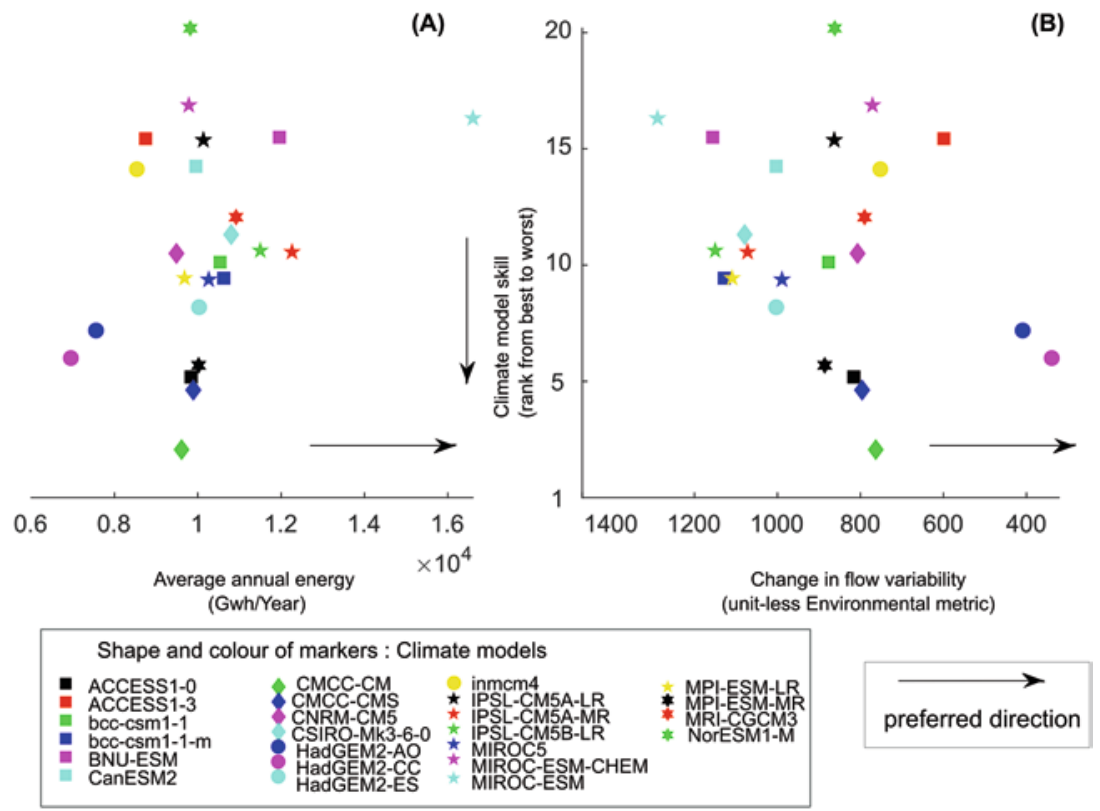

Fig. 6.5 (a) Total average energy performance and (b) change in seasonal flow variability as an indicator of impact on environmental flows, for all climate projections (ranked by skill on the y-axis, from 1 [best] to 24 [worst]) for the Rufiji River Basin where all development options are implemented and the reservoir release rules are set to maximise the minimum performance in any one of the climate projections

Figure 6.5a shows that total average energy generation for the Rufiji system reservoirs varies considerably between the climate model projections but without any apparent association with climate model skill (assessed using Method 2, 'model weighting by skill and dependence'). The majority of projections for the hydropower performance are close to that obtained for the best-ranked model, a power generation of around 10,000 Gwh/ year for the Rufiji. Taking into account the skill of climate models can help us understand and communicate to decision-makers the plausibility of the range in outcomes. The model that predicts the highest annual energy generation (MIROC-ESM) is an outlier; it also has low climate model skill and could be a case for exclusion. If we give credence to climate model skill, it would suggest the hydropower potential of the Rufiji River Basin 
is more likely to be at or below $10,000 \mathrm{Gwh} /$ year, than above this level (Fig. 6.5a). Such information could be useful in planning for future energy availability, for example, to design plans for additional energy sources as a contingency for less productive projections becoming reality.

Projections of environmental performance show a wide spread with a slight pattern for greater negative impacts on seasonal flow variability, especially for lower ranked climate models (Fig. 6.5b). The higher ranked HadGEM2-CC and HadGEM2-AO projections score relatively well for flow variability even though their total energy generation is the lowest of all.

For this dam and irrigation expansion development combination in the Rufiji, the assessment of climate model skill does not give a consistent result in terms of the impacts on hydropower or environmental flow performance. For both the energy generation and environmental metrics, the Rufiji performs at a similar level under the projections by the best ranked (CMCC-CM) and worst ranked (NorESMl-M) climate model.

\section{Discussion and Recommendations}

Weighting of climate model projections gives some insight into the range of uncertainty, but for this region and set of models, it does not produce a consistent relationship between model realism in simulating regional climate and the direction and magnitude of its rainfall projection and how this translates into key impacts in the basin. Low- and high-performing models project both wetter and drier conditions. Even when excluding the most extreme projections, considerable uncertainty remains. Processbased weighting (Method 3 here) gives most insight into reasons for model divergence and allows for some model exclusion, but the method requires considerable resources, scientific expertise and value judgements such that standardising it would be very difficult.

The Rufiji River Basin is located in south-east Africa, a climate system transition zone, where complex responses to global and regional teleconnections result in high rainfall variability and lack of model consensus about future rainfall change (Siderius et al. 2020). This complicates model evaluation and limits the value of model weighting to uncertainty reduction-we therefore caution against extrapolating our findings. In other regions, model weighting might provide a more distinctive split between 'good' and 'bad' models, though others (Rowell et al. 2016; Sanderson et al. 2017) have found similar inconclusive results to ours. 
The translation of climate change into runoff through the use of hydrological models enhances the range of uncertainty. While rainfall projections suggest a higher likelihood of wetter conditions over the Rufiji River Basin, when taking into account increased temperatures and the likelihood of changing seasonality in rainfall, the split in terms of impacts on runoff between wet and dry projections is similar. The range of uncertainty is further modified when climate or hydrological indicators are translated into specific sector performance indicators such as failure to provide monthly firm energy production. We could not address two other important technical sources of uncertainty in this chapter: poorly understood hydrology of large ungauged tributaries which limits the reliability of the crop-hydrology and water resources models (Siderius et al. 2018); and while we use only one impact model, others have shown that different impact models have different climate sensitivities.

Management and governance also play a crucial role in determining which options are selected and the extent to which policies are implemented. For example, our basin development scenario is highly ambitious in terms of irrigation expansion, and optimisation of dam releases assumes coordination of existing and planned reservoirs, something that is not guaranteed. Cross-sectoral coordination between line ministries such as water, energy and agriculture has been limited in practice (Pardoe et al. 2018a).

Climate change projections are not routinely integrated into planning and decision-making in Tanzania. While Tanzania's Meteorological Agency recognises the increasing importance of climate change, their focus is primarily on providing daily, ten-day and seasonal forecasts. With limited funding, they tend to prioritise model resolution over model inclusion (e.g. Luhunga et al. 2018). Our results indicate the importance of including information from a range of models, rather than the use of just one or an average of many.

Our findings are part of a four-year scientific research project involving several research groups and over 15 senior scientists, postdocs and Ph.D. students. Given operational realities, especially in low-income countries, where climate research has to compete with a multitude of other development priorities, this level of analysis (in terms of capacity and finance) is unlikely to be available. However, in terms of specific cost, the budget required to undertake a Rufiji climate risk assessment is small compared to the cost of major infrastructure such as the JNHPP and the potential costs of future underperformance. 
In this study, international academics collaborated with academics in Tanzania. In the Rufiji River Basin, the Rufiji Basin Water Board and the Ministry of Water and Irrigation are responsible for monitoring and managing water resources, with some external financial and technical support from various international research and development projects, and consultancies, often on an ad hoc basis with limited coordination. Daily operations (e.g. monitoring and permit processing) absorb most staff duties, time and resources. Both organisations have limited capacity to keep up with the evolving knowledge on climate projections and the complexity of methods and range of uncertainties, alongside rapid innovation in DMUU approaches. We saw that regular interactions with local academics acting as consultants, hosting students for research dissertations and often subsequently employing them means that strong links exist between research and practice. However, constraints on teaching and research in many universities and parallel issues in line ministries limit the degree to which new insights can be adopted. To improve capacity and embed and operationalise DMUU approaches such as those presented here will require continued funding and collaboration, including scholarships to train early career researchers in the latest techniques, and to create a stimulating work environment with competitive salaries to retain staff (Pardoe et al. 2018b). While this project did not have a formal agreement to feed into actual decisions in the basin, the regular interactions with formal institutions raises awareness about climate risk, and the strengths and weaknesses of tools and approaches for DMUU.

In conclusion, we find that in this example, the model weighting approaches do not greatly reduce the inter-model uncertainty, but it can be better understood. Planning decisions would still need to consider performance under multiple plausible futures (robustness), and decisions about infrastructure should prioritise cases with more easily reversible options (or delay major irreversible decisions) and greater flexibility such as in the design of reservoir operating rules and regular review of contingency plans. While significant hydropower capacity will be added to the Tanzanian grid by the JNHPP, the reservoir and other interventions need to be able to cope with changes in hydro-climatic variability. Adaptive management will be required to secure reliable energy supply and mitigate the impact of the JNHPP reservoir on the Rufiji's downstream delta ecosystem. 


\section{REFERENCES}

Conway, D., \& Schipper, E. L. F. (2011). Adaptation to climate change in Africa: Challenges and opportunities identified from Ethiopia. Global Environmental Change, 21(1), 227-237.

Duvail, S., Mwakalinga, A., Eijkelenburg, A., Hamerlynck, O., Kindinda, K., \& Majule, A. (2014). Jointly thinking the post-dam future: Exchange of local and scientific knowledge on the lakes of the Lower Rufiji, Tanzania. Hydrological Sciences Journal, 59(3-4), 713-730.

Famien, A. M., Janicot, S., Ochou, A. D., Vrac, M., Defrance, D., Sultan, B., \& Noël, T. (2018). A bias-corrected CMIP5 dataset for Africa using the CDF-t method - A contribution to agricultural impact studies. Earth System Dynamics, 9(1), 313-338.

Geressu, R., Siderius, C., Harou, J. J., Kashaigili, J., Pettinotti, L., \& Conway, D. (2020). Assessing river basin development given water-energy-foodenvironment interdependencies. Earth's Future, e2019EF001464.

Giorgi, F., Jones, C., \& Asrar, G. R. (2009). Addressing climate information needs at the regional level: The CORDEX framework. World Meteorological Organization (WMO) Bulletin, 58(3), 175.

Global Commission on Adaptation. (2019). Adapt Now: A Global Call for Leadership on Climate Resilience. Global Center on Adaptation and World Resources Institute.

Hallegatte, S., Shah, A., Brown, C., Lempert, R., \& Gill, S. (2012). Investment decision making under deep uncertainty - Application to climate change. The World Bank. https://doi.org/10.1596/1813-9450-6193

Harris, I., Jones, P. D., Osborn, T. J., \& Lister, D. H. (2014). Updated highresolution grids of monthly climatic observations - The CRU TS3.10 dataset. International Journal of Climatology, 34(3), 623-642.

Knutti, R., Furrer, R., Tebaldi, C., Cermak, J., \& Meehl, G. A. (2010). Challenges in combining projections from multiple climate models. Journal of Climate, 23(10), 2739-2758.

Kolusu, S. R., Siderius, C., Todd, M. C., Bhave, A., Conway, D., James, R., Washington, R., Geressu, R., Harou, J. J., \& Kashaigili, J. J. (2021). Sensitivity of projected climate impacts to climate model weighting. Climatic Change (in press).

Lempert, R. J., \& Schlesinger, M. E. (2000). Robust strategies for abating climate change. Climatic Change, 45(3-4), 387-401.

Luhunga, P. M., Kijazi, A. L., Chang'a, L., Kondowe, A., Ng’ongolo, H., \& Mtongori, H. (2018). Climate change projections for tanzania based on highresolution regional climate models from the coordinated regional climate downscaling experiment (CORDEX)-Africa. Frontiersin Environmental Science, 6, 122.

Nissan, H., Goddard, L., de Perez, E. C., Furlow, J., Baethgen, W., Thomson, M. C., \& Mason, S. J. (2019). On the use and misuse of climate change 
projections in international development. Wiley Interdisciplinary Reviews: Climate Change, 10(3), e579.

Pardoe, J., Conway, D., Namaganda, E., Vincent, K., Dougill, A. J., \& Kashaigili, J. J. (2018a). Climate change and the water-energy-food nexus: insights from policy and practice in Tanzania. Climate Policy, 18(7), 863-877.

Pardoe, J., Vincent, K., \& Conway, D. (2018b). How do staff motivation and workplace environment affect capacity of governments to adapt to climate change in developing countries? Environmental Science \& Policy, 90, 46-53.

Ray, P. A., \& Brown, C. M. (2015). Confronting climate uncertainty in water resources planning and project design: The decision tree framework. Washington, DC: The World Bank.

Rowell, D. P. (2019). An observational constraint on CMIP5 projections of the East African long rains and Southern Indian Ocean warming. Geophysical Research Letters, 46(11), 6050-6058.

Rowell, D. P., Senior, C. A., Vellinga, M., \& Graham, R. J. (2016). Can climate projection uncertainty be constrained over Africa using metrics of contemporary performance? Climatic Change, 134(4), 621-633.

Sanderson, B. M., Wehner, M., \& Knutti, R. (2017). Skill and independence weighting for multi-model assessments. Geoscientific Model Development, 10(6), 2379-2395.

Schneider, U., Finger, P., Meyer-Christoffer, A., Rustemeier, E., Ziese, M., \& Becker, A. (2017). Evaluating the hydrological cycle over land using the newlycorrected precipitation climatology from the Global Precipitation Climatology Centre (GPCC). Atmosphere, 8(3), 52.

Siderius, C., Biemans, H., Kashaigili, J. J., \& Conway, D. (2018). Going local: Evaluating and regionalizing a global hydrological model's simulation of river flows in a medium-sized East African Basin. Journal of Hydrology: Regional Studies.

Siderius, C., Kolussu, S., Conway, D., Todd, M., Bhave, A., Washington, R., Hart, N., James, R., Kashaigili, J. J., \& Mkwambisi, D. (2020). Climate variability impacts water-energy-food infrastructure performance in Eastern Africa. One Earth (In review).

Tanzania Government. (2016). Power system master plan 2016 update. Ministry of Energy and Minerals, Dar es Salaam.

UMFULA. (2019). The current and future climate of Central and Southern Africa: What we have learnt and what it means for decision-making in Malawi and Tanzania. Cape Town: Future Climate for Africa.

WREM International. (2015). Rufiji Basin IWRMD plan: Final report volume I: Technical report prepared for the United Republic of Tanzania, Ministry of Water (p. 206). Atlanta: WREM International Inc.

WWF International. (2017). The true cost of power: The facts and risks of building Stiegler's Gorge Hydropower Dam in Selous Game Reserve, Tanzania. Gland. 
Open Access This chapter is licensed under the terms of the Creative Commons Attribution 4.0 International License (http://creativecommons.org/licenses/ by $/ 4.0 /$ ), which permits use, sharing, adaptation, distribution and reproduction in any medium or format, as long as you give appropriate credit to the original author(s) and the source, provide a link to the Creative Commons licence and indicate if changes were made.

The images or other third party material in this chapter are included in the chapter's Creative Commons licence, unless indicated otherwise in a credit line to the material. If material is not included in the chapter's Creative Commons licence and your intended use is not permitted by statutory regulation or exceeds the permitted use, you will need to obtain permission directly from the copyright holder. 